\title{
Sleep in Early Modern England
}

Review Number: 2061

Publish date: Thursday, 9 February, 2017

Author: Sasha Handley

ISBN: 9780300220391

Date of Publication: 2016

Price: $£ 25.00$

Pages: 296pp.

Publisher: Yale University Press

Publisher url: http://yalebooks.co.uk/display.asp?k=9780300220391

Place of Publication: New Haven, CT

Reviewer: Olivia Weisser

In early modern England sleep was a ritualized form of devotion, a means of staving off illness, a source of solace, and marker of sociability. In short, it was both a physical and cultural practice. Sleep in Early Modern England by Sasha Handley does not recover a uniform system of sleep wholly distinct from our own, but instead shows how understandings of sleep varied by individual preferences, resources, spiritual sentiments, and environmental landscapes. The study is most valuable for showing how something as routine as sleep can open a window onto the physical, spiritual, and emotional lives of the past. The author tends to favor the word 'practice', perhaps as a reminder that sleep, like so many embodied acts, is culturally produced. It may be natural and necessary, but it is also historically specific.

The book opens by exploring how sleep was believed to operate within the body in the early modern period. This initial chapter traces a broader shift from a framework of the body based on humors to one centered on nerves. After laying out the details of these explanatory models, the book examines how changing ideas about health and sleep affected behaviors in the home. Cleaning routines and bedding choices were endowed not only with cultural meanings, but also medical ones. For example, a preference for linen sheets was reinforced by the notion that cool, stiff fibers regulated the body and prevented the infiltration of bugs. An even more comprehensive discussion of the 'nervous body' would have helped contextualize these shifting views. Readers without a background in the history of medicine may not know that 18th-century theories of nerves bear little resemblance to the modern field of neurology. Additional historical context would clarify such distinctions and complicate the author's characterization of this story as one of 'sleep's medicalisation' (pp. 20,212). This phrase suggests a progressive narrative of change that paints humoralism as less medical than nervous physiology. But sleep quality was central to health within both models of medicine.

The book moves from the physical to spiritual by looking at the role of sleep in early modern devotional practice. This discussion examines the links between sleep and ideas about death, prayers, and godly reading, as well as ways of sanctifying the bedchamber. The author uses the phrase 'sleep piety' to capture all of these sleep-related religious practices, and suggests that they became more firmly embedded after 1660 when public worship was prohibited or curtailed for many Protestants and Catholics. The private home, as a result, became a key site for devotional practice. Handley nobly gathers evidence from a range of confessional affiliations and finds overlaps, as well as subtle differences, in the fervency and frequency of 
sleep piety.

The book also examines prayers uttered around bedsteads as men and women tried to fill their minds with pious thoughts to safeguard their souls through the night. Sermons further reveal how believers learned to practice sleep piety. They were instructed to cultivate sleep habits that preserved time for work and worship, and to view bad sleep as damaging because it dulled the senses and made believers less receptive to God's grace. In addition to prayers and sermons, Handley examines the bed itself as a site of worship. I wondered, too, about the role of beds in other types of early modern life events: ill health, childbirth, sexual assault, and so on.

This discussion of religion and sleep is thought provoking, although a few analytical points remain tentative. For instance, in her analysis of a piece of fabric with a pattern of trees, flowers, birds, and insects, the author writes that it 'may have brought to mind the perils that might be met during sleep' (p. 104). Handley is smart to use subtle language like 'may' and 'might,' as the pattern does not appear obviously perilous. Moreover, this particular piece of fabric was repurposed from another part of the house and presumably was not designed with sleep in mind.

The book delves more deeply into the material history of sleep using 115 probate inventories from the Prerogative Court of Canterbury from 1660-1760. This source reveals the relocation of bedsteads from multifunctional ground floors to semi-specialized chambers on upper floors, a shift that is linked to desires for security and enclosure. The inventories trace an increasing number of bedsteads per household, but those numbers were probably an underestimate since some beds were portable, gifted, or sold before the probate inventory was compiled. The book also charts the anxieties associated with sleeping far from home. Part of this story reflects an 18th-century shift toward socializing in ways that disrupted sleep patterns. The growing popularity of plays, operas, and spas had an impact on the rhythms of sleep, and homes became increasingly equipped to accommodate overnight guests. The inventories show, for example, temporary bedsteads listed alongside surplus bedding. Such items were possibly used for visitors.

The book ends with a return to nerves and how this new framework for thinking about sleep and health also led to new ways of thinking about the self. Sleep was increasingly viewed as an external sign of the internal state of the nerves. It therefore served as an important barometer of mental agility and morality - key determinants of selfhood. This discussion centers on learned writing about restorative sleep as a means of preserving physical and mental acuity, and ends with a look at artistic and personal writing about sleep disorders. A key source is a series of reflections by Samuel Taylor Coleridge on the relationships between sleep quality and his own imagination.

There is much to appreciate about this book and there are a few ways the author might have reframed her ideas to highlight what is so unique and significant about them. The study charts several changes over time such as varying models of the body and the shifting location of bedsteads - but there is less of a sense of what, together, those changes mean for sleep as a whole. More explicit discussion of the study's timeframe would further clarify the points about change, as well. It is not always apparent whether purported changes are underway or have become fully rooted in popular consciousness. The juxtaposition of sources spanning nearly a hundred years adds to this uncertainty. For example, one chapter discusses John Wesley (1783) alongside the healthcare advice of Thomas Tryon (1693). The book's emphasis on change makes such comparisons - which otherwise might be unproblematic - a bit befuddling.

Finally, there are several instances in which the historical evidence does not seem to illustrate the author's analytical points. For example, one chapter looks at stories recounted by diarists Ralph Josselin and Alice Thornton. Both episodes entailed near-fatal accidents in bedrooms: a child fell into the fire and a maid set down a candle that lit a wooden bowl. Josselin and Thornton recorded these events to expound on God's mercy, since no one was hurt in either instance. Handley contextualizes the stories in beliefs about providence and suggests that such beliefs 'had their roots in deep-seated perceptions of beds as sites of transition between the earthly and spiritual realms' (p. 96). That may be the case, but it is not evident in the 
examples from Josselin and Thornton. Although both accidents occurred near beds, neither story suggests beliefs about beds as transitional sites. Thornton and Josselin, in fact, recorded numerous similar accounts of near-fatal accidents and divine preservation throughout their writing. These two just happened to occur in bedchambers.

Another example concerns a lively discussion of members of the Wesley family who, upon sensing the presence of a ghost, leapt into bed and hid under the covers. Handley explains that the Wesley children showed a 'need to defend themselves during sleep,' as it was a 'perilous process of physical and spiritual transformation' (p. 106). The three examples, however, each involved wide-awake, fully clothed individuals. A fright caused them to jump into bed despite being dressed. Their stories show that beds provided comfort in moments of fear. But they do not convey concerns about defense during sleep, nor the physical and spiritual shifts that sleep entailed.

Sleep in Early Modern England is strongest when analyzing the affective and sensory experiences of slumber. William Cole chose to sleep in a small, foldable tent bed over his best bed because, Handley suggests, it reminded him of his time at Eton. He was miserable as a schoolboy and he probably found solace in his bed. We can never know for sure, but the link between Cole's anxieties as a boy and his bizarre preference for a tent bed as an adult is clever and convincing. Likewise, the author provides a beautiful discussion of Alice Thornton's emotional connection to her bed. Handley draws on Thornton's life as a mother of nine children, her grief upon witnessing her own mother's painful death, and the strife involved in marrying off her young daughter. All of this biographical information contextualizes Thornton's fears around losing her bed - a moment that, the author movingly shows, was far more complex than missing a valued possession. In Handley's hands, the seemingly mundane and familiar become imbued with emotional and cultural significance.

Source URL:https://reviews.history.ac.uk/review/2061

\section{Links}

[1] https://reviews.history.ac.uk/item/205930 